\title{
ИЗУЧЕНИЕ ТИПА ПРОТИВОМИКРОБНОГО ДЕЙСТВИЯ НОВЫХ СОЕДИНЕНИЙ, СИНТЕЗИРОВАННЫХ НА ОСНОВЕ ЗАМЕЩЕННЫХ БЕНЗАМИНОИНДОЛОВ
}

\author{
И. С. Степаненко ${ }^{\otimes}$, С. А. Ямашкин², Ю. А. Костина ${ }^{1}$, Е. Д. Сластников ${ }^{1}$, А. А. Батаршева
}

Медицинский институт, Национальный исследовательский Мордовский государственный университет имени Н. П. Огарёва, Саранск, Россия

${ }^{2}$ Мордовский государственный педагогический институт имени М. Е. Евсевьева, Саранск, Россия

\begin{abstract}
Исследование противомикробной активности новых соединений включает изучение как минимальной подавляющей концентрации вещества, так и других показателей, в том числе - определение типа противомикробного действия. Целью работы было определить тип противомикробного действия новых соединений, синтезированных на основе замещенных бензаминоиндолов. Тип противомикробного действия определяли при воздействии исследуемых соединений с лабораторными шифрами 5D, 7D, HD и S3 в коротких экспозициях с использованием тест-штамма микроорганизма Staphylococcus aureus ATCC 6538-P. Рост микроорганизмов в присутствии исследуемых соединений определяли невооруженным глазом в проходящем свете и по изменению оптической плотности культуральной среды фотоколориметрически. Исследуемые соединения задерживали рост тест-штамма S. aureus в течение 2-3 и более суток и оказывали бактериостатическое действие в минимальных подавляющих концентрациях.
\end{abstract}

Ключевые слова: бензаминоиндолы, пирролохинолоны, противомикробная активность, тип противомикробного действия

Информация о вкладе авторов: И. С. Степаненко - участие в реализации экперимента, анализ полученных результатов; С. А. Ямашкин - синтез тестируемых соединений и консультирование по идее исследования; Ю. А. Костина - разработка дизайна статьи и анализ полученных результатов; А. А. Батаршева и Е. Д. Сластников - участие в реализации эксперимента.

$\triangle$ Для корреспонденции: Ирина Семеновна Степаненко

ул. Ульянова, д. 26, г. Саранск, 430032; ymahkina@mail.ru

Статья получена: 21.11.2018 Статья принята к печати: 07.04.2019 Опубликована онлайн: 21.04.2019

DOI: $10.24075 /$ vrgmu.2019.030

\section{A STUDY OF THE TYPE OF ANTIMICROBIAL ACTION OF NOVEL COMPOUNDS SYNTHESIZED FROM SUBSTITUTED BENZAMINOINDOLES}

Stepanenko IS ${ }^{1 凶}$, Yamashkin $S^{2}{ }^{2}$, Kostina YuA ${ }^{1}$, Slastnikov ED ${ }^{1}$, Batarsheva $A^{1}{ }^{1}$

${ }^{1}$ Institute of Medicine, National Research Mordovia State University, Saransk, Russia

${ }^{2}$ Evseviev Mordovia State Institute of Pedagogy, Saranks, Russia

The antimicrobial activity of novel compounds is tested by determining the minimum inhibitory concentration of the agent in question and investigating a few other parameters, including the type of antimicrobial action the drug exhibits. The aim of this study was to determine the type of antimicrobial action of the compounds synthesized from the substituted benzaminoindoles. The strain of Staphylococcus aureus ATCC 6538-P was briefly exposed to the compounds with laboratory codes 5D, 7D, HD, and S3. Bacterial growth was evaluated macroscopically under transmitted light. Additionally, photoelectric colorimetry was applied to monitor changes in the optical density of the culture medium. The minimum inhibitory concentrations of the studied compounds delayed bacterial growth for $2-3$ days and had a bacteriostatic effect on $S$. aureus.

Keywords: benzaminoindole, pyrroloquinoline, antimicrobial activity, antimicrobial activity type

Author contribution: Stepanenko IS conducted the experiment and analyzed its results; Yamashkin SA helped to design the experiment and synthesized the tested compounds; Kostina YuA analyzed the results of the experiment and wrote the article; Batarsheva AA and Slastnikov ED conducted the experiment.

$\triangle$ Correspondence should be addressed: Irina S. Stepanenko

Ulianova 26, Saranks, 430032; ymahkina@mail.ru

Received: 21.11.2018 Accepted: 07.04.2019 Published online: 21.04.2019

DOI: 10.24075/brsmu.2019.030

Борьба человечества с множеством патогенных микроорганизмов продолжается на протяжении многих веков. Открытие антимикробных агентов привело к успешному лечению и устранению некоторых бактериальных инфекций, однако выявило штаммы, устойчивые к противомикробным препаратам за счет многочисленных механизмов антибиотикорезистентности [1-3]. Проблема антибиотикорезистентности становится все более острой в XXI в., исследование механизмов приобретения устойчивости к антибимикробным агентам лежит в основе разработки новых способов борьбы с данным явлением $[4,5]$. Резистентность к лекарственным средствам представляет собой растущую глобальную угрозу для общественного здравоохранения, которая затрагивает все основные патогенные микрорганизмы и противомикробные средства [6, 7].

При проведении микробиологического мониторинга в течение последних лет отмечена тенденция к увеличению количества полирезистентных штаммов. Например, метициллинрезистентные S. aureus по сравнению с метициллин-чувствительными штаммами отличаются существенно более высокой частотой устойчивости к гентамицину, клиндамицину, рифампицину, тетрациклину, хлорамфениколу, цефтаролину, ципрофлоксацину и эритромицину; P. aeruginosa проявляет нечувствительность к антисинегнойным цефалоспоринам - цефепиму и цефтазидиму, а также пиперациллин-тазобактаму, имипенему, меропенему; представители семейства 
Enterobacteriaceae устойчивы к трем и более традиционно применяемым антибиотикам, таким как цефотаксим, цефтазидим, цефепим, азтреонам и др. [8-10].

Поиск и разработка новых противомикробных средств один из основополагающих принципов преодоления устойчивости микроорганизмов к антибиотикам. Необходимость поиска новых высокоэффективных и безопасных противомикробных соединений закреплена в Российской Федерации на законодательном уровне [11].

В результате реализации синтетических возможностей замещенных 4-, 5-, 6-, 7-аминоиндолов, используемых в качестве исходных веществ, нами была синтезирована серия индолиламидов и пирролохинолонов и доказано, что полученные новые соединения, представляющие собой различные замещенные циклические, нециклические $N$-(индолил)амиды и пирролохинолоны, обладают той или иной противомикробной активностью в отношении грамположительных и грамотрицательных микроорганизмов [12-14].

Целью исследования было определить тип противомикробного действия новых соединений, синтезированных на основе замещенных аминоиндолов.

\section{МАТЕРИАЛЫ И МЕТОДЫ}

Определение типа противомикробного действия проводили с использованием тест-штамма микроорганизма Staphylococcus aureus ATCC 6538-P (получен из коллекции музея живых культур ФБУН «ГНЦ ПМБ»). Для этого использовали методику воздействия исследуемых соединений в физиологическом растворе при комнатной температуре и коротких экспозициях [15]. Различные концентрации изучаемых соединений в физиологическом растворе разливали по пробиркам (по 1 мл). Контрольные пробирки не содержали исследуемых соединений. Одновременно готовили взвесь бактерий в физиологическом растворе и добавляли по 1 мл в пробирки, содержащие исследуемые соединения. Концентрация исследуемого микроорганизма в суспензии составляла 1,5 • 108 $\mathrm{KOE} / \mathrm{Mл.}$ Мутность бактериальной суспензии с концентрацией исследуемого микроорганизма 1,5 • 108 KOE/мл при визуальном контроле соответствует 0,5 по стандарту мутности МакФарланда $[16,17]$. В работе использовали коммерческий набор для определения стандарта мутности 0,5 по МакФарланду (Sensititre; UK). Контроль оптической плотности суспензии также осуществляли спектрофотометрически (денситометрически). Бактериальную суспензию готовили из агаровой суточной культуры. Отмечали время, а затем через 5, 10, 15 и 30 мин, 1, 2 и 4 ч с помощью микропипетки вносили по 100 мкл физиологического раствора, содержащих микроорганизмы и исследуемое соединение, в пробирки, содержащие 1 мл бульона МюллераХинтона (МХБ) (М391; HiMedia Laboratories Pvt. limited; Индия). Использование нескольких временных экспозиций при определенной дозе вещества является основной предпосылкой для оценки возможных и фактических воздействий. Такой мониторинг позволяет выявить имеющиеся на данный момент воздействия минимальной подавляющей концентрации (МПК) соединения и их изменения во времени. Свойства веществ могут меняться в зависимости от свойств среды и микроорганизмов [15].

Конечная концентрация исследуемого микроорганизма в суспензии составила примерно $5 \cdot 10^{5} \mathrm{KOE} /$ мл в каждой пробирке. Концентрация исследуемых соединений для циклического амида 5D была равна 25 мкг/мл, для циклического амида 7D - 125 мкг/мл, для амида S3 62,5 мкг/мл, циклического амида HD - 59 мкг/мл, азитромицина - 1 мкг/мл [11-13]. В качестве препарата сравнения был выбран азитромицин - классический препарат с бактериостатическим действием, МПК азитромицина для $S$. aureus составляет 0,01-2 мкг/мл [18]. Пробирки помещали в термостат при $37^{\circ} \mathrm{C}$ и наблюдали наличие роста микроорганизмов в течение 5 суток. Для определения наличия роста микроорганизма пробирки с посевами культуры патогена просматривали в проходящем свете. Дополнительно рост микроорганизмов фиксировали по изменению оптической плотности культуральной среды с использованием фотоэлектроколориметра Apel «AP-101» (ООО «Энергопромавтоматика»; Россия). Исследование проводили в объеме 1 мл в стерильных кюветах при длине волны 600 нм. Полученную оптическую плотность микроорганизмов, культивируемых в присутствии противомикробного соединения, сравнивали с оптической плотностью микроорганизмов, культивируемых без противомикробного соединения. В ходе исследования провели четыре серии эксперимента.

В работе исследовали соединения, полученные на основе замещенных 4-, 6- и 7-аминоиндолов.

1. Производное замещенного 4-амино-2-фенилиндола 4-гидрокси-8-фенил-4-(трифторметил)-1,3,4,7-тетрагидро2H-пирроло[2,3-h]хинолин-2-он - циклический амид (лабораторный шифр: 5D)<smiles>O=C1CC(O)(C(F)(F)Cl)c2ccc3[nH]c(-c4ccccc4)cc3c2N1</smiles>

2. Производные замещенных 6-аминоиндолов: N-(1,5-диметил-2-фенил-1Н-индол-6-ил)-4,4,4-трифтор-3оксобутанамид - нециклический амид (лабораторный шифр: S3)<smiles>Cc1cc2cc(-c3ccccc3)n(C)c2cc1NC(=O)CC(F)(F)F</smiles>

S3

3. 9-гидрокси-5-метил-2-фенил-9-(трифторметил)-1,6,8,9тетрагидро-7Н-пирроло[2,3-f]хинолин-7-он — циклический амид (лабораторный шифр: 7D)<smiles>Cc1cc2cc(-c3ccccc3)[nH]c2c2c1NC(=O)CC2(O)C(F)(F)F</smiles>

4. Производное замещенного 7-аминоиндола 6-гидрокси2,3-диметил-6-(трифторметил)-1,6, 7,9-тетрагидро-8Нпирроло[3,2-h]хинолин-8-он - циклический амид (лабораторный шифр: HD)<smiles></smiles>

HD 
Обозначения для исследуемых соединений представлены в соответствии с правилами компьютерной программы ACDLABS IUPAC Name Generator версия MarvinSketch 4.7.7.0. (ChemAxon Ltd.; Венгрия), а структурные формулы соединений были нарисованы в компьютерной программе ISIS Draw 2.4. версия 2.4. (MDL Information Systems; CШA)

Статистическую обработку полученных результатов проводили методами вариационной статистики, достоверность результатов оценивали с помощью метода определения t-критерия Стьюдента [16].

\section{РЕЗУЛЬТАТЫ ИССЛЕДОВАНИЯ}

Видимый рост микроорганизмов в питательной среде наблюдали при показателях оптической плотности (D) культуральной среды более 0,21. Культуральная среда с «Отрицательным» контролем микроорганизмов (5 • 105 KOЕ/мл

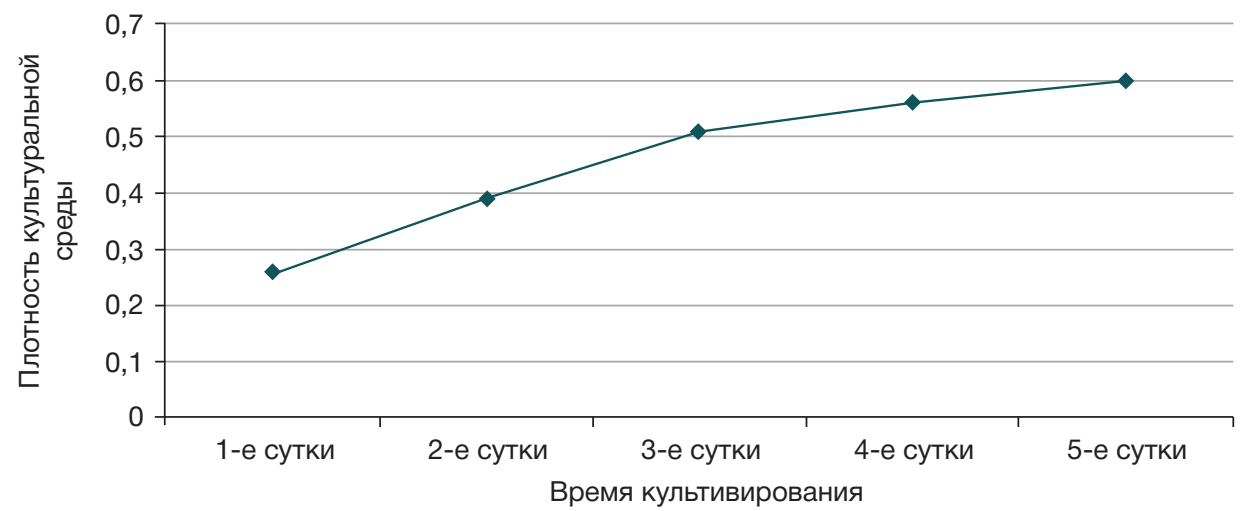

Рис. 1. Оптическая плотность культуральной среды с S. aureus ATCC 6538-P при культивировании в течение 5 суток

Таблица. Исследование роста S. aureus ATCC 6538-P по показателям оптической плотности культуральной средь

\begin{tabular}{|c|c|c|c|c|c|c|c|c|c|}
\hline & & \multicolumn{8}{|c|}{ Время экспозиции } \\
\hline $\begin{array}{c}\text { Время } \\
\text { исследования }\end{array}$ & Контроль & Соединения & 5 мин & 10 мин & 5 мин & 30 мин & 14 & 24 & 44 \\
\hline \multirow{6}{*}{ 1-е сутки } & \multirow{6}{*}{$0,26 \pm 0,03$} & Контроль & $0,22 \pm 0,01$ & $0,22 \pm 0,02$ & $0,25 \pm 0,04$ & $0,26 \pm 0,02$ & $0,23 \pm 0,05$ & $0,27 \pm 0,03$ & $0,25 \pm 0,02$ \\
\hline & & Азитромицин & $0,05 \pm 0,01^{*}$ & $0,05 \pm 0,01^{*}$ & $0,05 \pm 0,01^{*}$ & $0,05 \pm 0,01^{*}$ & $0,07 \pm 0,03^{\star}$ & $0,07 \pm 0,02^{*}$ & $0,06 \pm 0,01^{*}$ \\
\hline & & $\mathrm{HD}$ & $0,07 \pm 0,01^{*}$ & $0,07 \pm 0,02^{*}$ & $0,07 \pm 0,01^{\star}$ & $0,08 \pm 0,03^{*}$ & $0,07 \pm 0,01^{*}$ & $0,06 \pm 0,02^{*}$ & $0,05 \pm 0,001^{*}$ \\
\hline & & S3 & $0,12 \pm 0,02^{*}$ & $0,12 \pm 0,02^{*}$ & $0,10 \pm 0,01^{*}$ & $0,10 \pm 0,02^{*}$ & $0,09 \pm 0,03^{*}$ & $0,09 \pm 0,02^{*}$ & $0,09 \pm 0,02^{*}$ \\
\hline & & 7D & $0,07 \pm 0,02^{*}$ & $0,07 \pm 0,02^{*}$ & $0,07 \pm 0,01^{*}$ & $0,08 \pm 0,02^{*}$ & $0,06 \pm 0,01^{*}$ & $0,06 \pm 0,01^{*}$ & $0,06 \pm 0,01^{*}$ \\
\hline & & $5 \mathrm{D}$ & $0,010 \pm 0,001^{*}$ & $0,010 \pm 0,001^{\star}$ & $0,010 \pm 0,001^{*}$ & $0,010 \pm 0,003^{*}$ & $0,010 \pm 0,001^{*}$ & $0,010 \pm 0,001^{*}$ & $0,010 \pm 0,002^{*}$ \\
\hline \multirow{6}{*}{ 2-е сутки } & \multirow{6}{*}{$0,39 \pm 0,06$} & Контроль & $0,38 \pm 0,07$ & $0,38 \pm 0,09$ & $0,38 \pm 0,12$ & $0,37 \pm 0,08$ & $0,43 \pm 0,09$ & $0,39 \pm 0,04$ & $0,44 \pm 0,01$ \\
\hline & & Азитромицин & $0,09 \pm 0,06^{*}$ & $0,09 \pm 0,05^{*}$ & $0,12 \pm 0,04^{*}$ & $0,15 \pm 0,02^{*}$ & $0,15 \pm 0,01^{*}$ & $0,15 \pm 0,04^{*}$ & $0,11 \pm 0,02^{*}$ \\
\hline & & HD & $0,18 \pm 0,04^{*}$ & $0,18 \pm 0,02^{*}$ & $0,15 \pm 0,03^{*}$ & $0,14 \pm 0,03^{*}$ & $0,09 \pm 0,01^{*}$ & $0,08 \pm 0,01^{*}$ & $0,07 \pm 0,02^{*}$ \\
\hline & & S3 & $0,25 \pm 0,02$ & $0,27 \pm 0,02$ & $0,24 \pm 0,03$ & $0,20 \pm 0,01^{*}$ & $0,19 \pm 0,03^{\star}$ & $0,20 \pm 0,01^{*}$ & $0,20 \pm 0,01^{*}$ \\
\hline & & $7 \mathrm{D}$ & $0,15 \pm 0,04^{*}$ & $0,15 \pm 0,02^{*}$ & $0,14 \pm 0,03^{*}$ & $0,19 \pm 0,04^{\star}$ & $0,15 \pm 0,02^{\star}$ & $0,15 \pm 0,01^{*}$ & $0,13 \pm 0,03^{*}$ \\
\hline & & $5 \mathrm{D}$ & $0,011 \pm 0,002^{*}$ & $0,012 \pm 0,001^{\star}$ & $0,012 \pm 0,002^{*}$ & $0,011 \pm 0,002^{*}$ & $0,011 \pm 0,001^{*}$ & $0,011 \pm 0,003^{*}$ & $0,011 \pm 0,002^{*}$ \\
\hline \multirow{6}{*}{ 3-е сутки } & \multirow{6}{*}{$0,51 \pm 0,05$} & Контроль & $0,45 \pm 0,02$ & $0,45 \pm 0,04$ & $0,48 \pm 0,02$ & $0,49 \pm 0,08$ & $0,51 \pm 0,03$ & $0,46 \pm 0,02$ & $0,51 \pm 0,01$ \\
\hline & & Азитромицин & $0,13 \pm 0,07^{*}$ & $0,13 \pm 0,05^{*}$ & $0,17 \pm 0,02^{*}$ & $0,20 \pm 0,01^{*}$ & $0,20 \pm 0,01^{*}$ & $0,19 \pm 0,02^{*}$ & $0,18 \pm 0,02^{*}$ \\
\hline & & HD & $0,28 \pm 0,11$ & $0,28 \pm 0,08$ & $0,28 \pm 0,02$ & $0,24 \pm 0,05^{\star}$ & $0,22 \pm 0,03^{\star}$ & $0,21 \pm 0,04^{*}$ & $0,23 \pm 0,02^{*}$ \\
\hline & & S3 & $0,32 \pm 0,1$ & $0,32 \pm 0,07$ & $0,34 \pm 0,04$ & $0,29 \pm 0,5$ & $0,29 \pm 0,04$ & $0,27 \pm 0,05$ & $0,26 \pm 0,03$ \\
\hline & & 7D & $0,18 \pm 0,03^{*}$ & $0,18 \pm 0,02^{*}$ & $0,17 \pm 0,01^{*}$ & $0,25 \pm 0,04$ & $0,20 \pm 0,01^{*}$ & $0,19 \pm 0,01^{*}$ & $0,18 \pm 0,01^{*}$ \\
\hline & & $5 \mathrm{D}$ & $0,014 \pm 0,002^{*}$ & $0,013 \pm 0,003^{\star}$ & $0,014 \pm 0,003^{*}$ & $0,02 \pm 0,007^{\star}$ & $0,014 \pm 0,002^{*}$ & $0,02 \pm 0,002^{*}$ & $0,02 \pm 0,002^{*}$ \\
\hline \multirow{6}{*}{ 4-е сутки } & \multirow{6}{*}{$0,56 \pm 0,02$} & Контроль & $0,53 \pm 0,01$ & $0,53 \pm 0,03$ & $0,56 \pm 0,03$ & $0,56 \pm 0,01$ & $0,58 \pm 0,01$ & $0,54 \pm 0,01$ & $0,57 \pm 0,01$ \\
\hline & & Азитромицин & $0,24 \pm 0,05^{\star}$ & $0,25 \pm 0,03^{*}$ & $0,27 \pm 0,07$ & $0,33 \pm 0,03$ & $0,34 \pm 0,02$ & $0,25 \pm 0,03$ & $0,23 \pm 0,03^{*}$ \\
\hline & & $\mathrm{HD}$ & $0,35 \pm 0,09$ & $0,35 \pm 0,12$ & $0,36 \pm 0,09$ & $0,36 \pm 0,10$ & $0,32 \pm 0,07$ & $0,36 \pm 0,09$ & $0,30 \pm 0,06$ \\
\hline & & S3 & $0,42 \pm 0,03$ & $0,42 \pm 0,04$ & $0,39 \pm 0,02$ & $0,36 \pm 0,03$ & $0,35 \pm 0,06$ & $0,35 \pm 0,04$ & $0,33 \pm 0,04$ \\
\hline & & 7D & $0,27 \pm 0,02$ & $0,27 \pm 0,04$ & $0,27 \pm 0,06$ & $0,33 \pm 0,03$ & $0,33 \pm 0,04$ & $0,25 \pm 0,03$ & $0,23 \pm 0,01^{*}$ \\
\hline & & $5 \mathrm{D}$ & $0,03 \pm 0,007^{\star}$ & $0,03 \pm 0,008^{\star}$ & $0,03 \pm 0,003^{\star}$ & $0,04 \pm 0,011^{\star}$ & $0,07 \pm 0,013^{\star}$ & $0,07 \pm 0,01^{*}$ & $0,09 \pm 0,01^{*}$ \\
\hline \multirow{6}{*}{ 5-е сутки } & \multirow{6}{*}{$0,60 \pm 0,02$} & Контроль & $0,54 \pm 0,03$ & $0,54 \pm 0,05$ & $0,57 \pm 0,03$ & $0,57 \pm 0,01$ & $0,59 \pm 0,01$ & $0,55 \pm 0,04$ & $0,58 \pm 0,03$ \\
\hline & & Азитромицин & $0,25 \pm 0,05^{*}$ & $0,26 \pm 0,02^{*}$ & $0,28 \pm 0,09$ & $0,38 \pm 0,1$ & $0,36 \pm 0,06$ & $0,26 \pm 0,02^{*}$ & $0,25 \pm 0,01^{*}$ \\
\hline & & $\mathrm{HD}$ & $0,43 \pm 0,05$ & $0,43 \pm 0,09$ & $0,43 \pm 0,06$ & $0,53 \pm 0,05$ & $0,43 \pm 0,09$ & $0,46 \pm 0,04$ & $0,37 \pm 0,9$ \\
\hline & & S3 & $0,43 \pm 0,06$ & $0,43 \pm 0,05$ & $0,40 \pm 0,13$ & $0,37 \pm 0,11$ & $0,36 \pm 0,07$ & $0,35 \pm 0,04$ & $0,35 \pm 0,03$ \\
\hline & & 7D & $0,31 \pm 0,12$ & $0,31 \pm 0,09$ & $0,31 \pm 0,04$ & $0,42 \pm 0,05$ & $0,35 \pm 0,02$ & $0,31 \pm 0,03$ & $0,25 \pm 0,02^{*}$ \\
\hline & & $5 \mathrm{D}$ & $0,04 \pm 0,009^{*}$ & $0,04 \pm 0,01^{*}$ & $0,06 \pm 0,012^{\star}$ & $0,07 \pm 0,011^{*}$ & $0,08 \pm 0,002^{*}$ & $0,09 \pm 0,01^{*}$ & $0,11 \pm 0,01^{*}$ \\
\hline
\end{tabular}

Примечание: * — отличие от контроля статистически достоверно при $p<0,05$. 
микроорганизма), хранившаяся в холодильнике, имеет значение $D=0,003$.

В контрольных пробирках видимый рост микроорганизмов наблюдали через сутки после посева (рис. 1). Показатели оптической плотности культуральной среды после первых суток культивирования демонстрировали прирост микробной массы до 0,26 и более (табл.). Через 2 суток культивирования значение $D$ микробной популяции S. aureus ATCC 6538-P достигло 0,39, через 3 суток - 0,51, через 4 суток - 0,56, через 5 суток культивирования этот показатель составил 0,6. Таким образом, в течение эксперимента наблюдали прирост микробной популяции на 50\%, на 30\%, на 9\%, на 7\% после 2, 3, 4 и 5 суток культивирования соответственно (рис. 2). Снижение интенсивности роста можно объяснить истощением ресурсов питательной среды.

Препарат сравнения азитромицин задерживал рост и размножение тест-штамма S. aureus в течение 3 суток. После 4-суточного культивирования с азитромицином в МПК наблюдали появление видимого роста микробной популяции в проходящем свете (рис. 3). Увеличение плотности культуральной среды после экспозиций с азитромицином наблюдали после 2 суток культивирования (табл.). Показатели величины $D$ культуральной среды статистически значимо отличались от таковых в контроле ( $<$ < 0,05). После 4 суток культивирования тест-штамма отмечали увеличение плотности культуральной среды относительно исходной до 0,23-0,25, но задержка роста микробной популяции оставалась статистически значимо отличной от контроля в течение всего эксперимента. Запоздалый (через 4 суток) рост свидетельствует об отсутствии бактерицидного действия. МПК азитромицина задерживает рост и размножение микроорганизмов и оказывает в исследуемой концентрации бактериостатическое действие.

После экспозиции тест-штамма с циклическим амидом HD видимого в проходящем свете роста в первые сутки не наблюдали. Через 2 суток культивирования роста микроорганизмов во всех пробирках невооруженным глазом не выявили. Через 3 суток наблюдения обнаружили видимое помутнение среды во всех пробирках с посевами. Значение $D$ культуральной среды после первых суток наблюдения свидетельствует о задержке роста и размножения тест-штамма S. aureus ATCC 6538-P после экспозиций с исследуемым соединением (табл.; рис. 4). После культивирования в течение 2 суток циклический амид HD статистически значимо задерживал рост микробной популяции $(p<0,05)$. В течение всего эксперимента

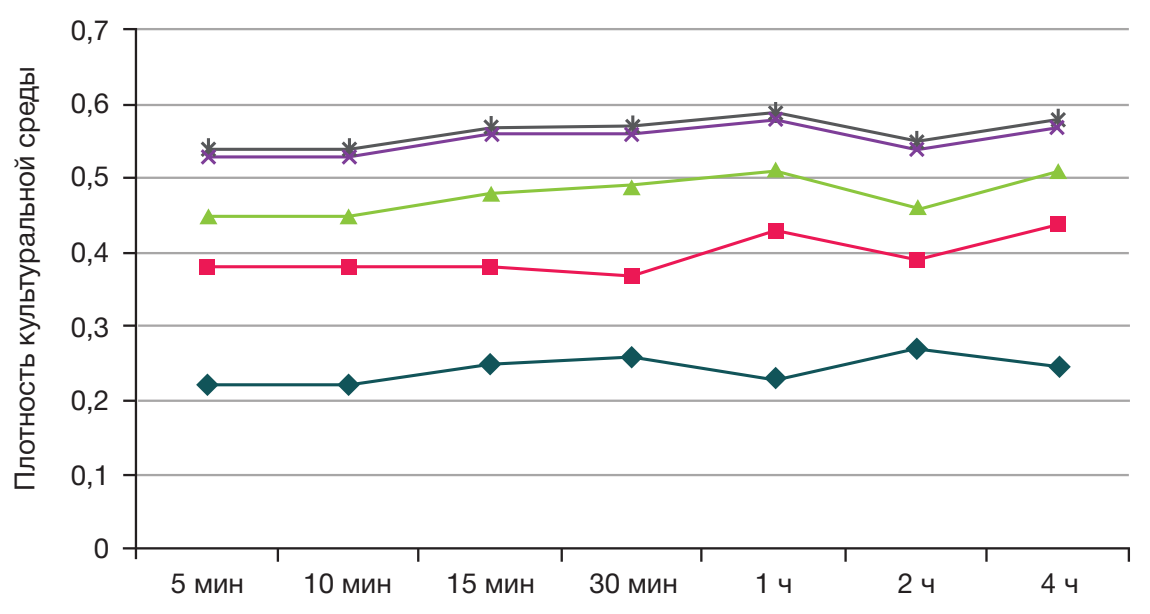

Время экспозиции в физиологическом растворе

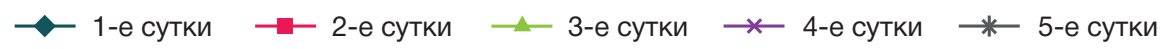

Pис. 2. Оптическая плотность культуральной среды с S. aureus ATCC 6538-P после экспозиций в физиологическом растворе при культивировании в течение 5 суток

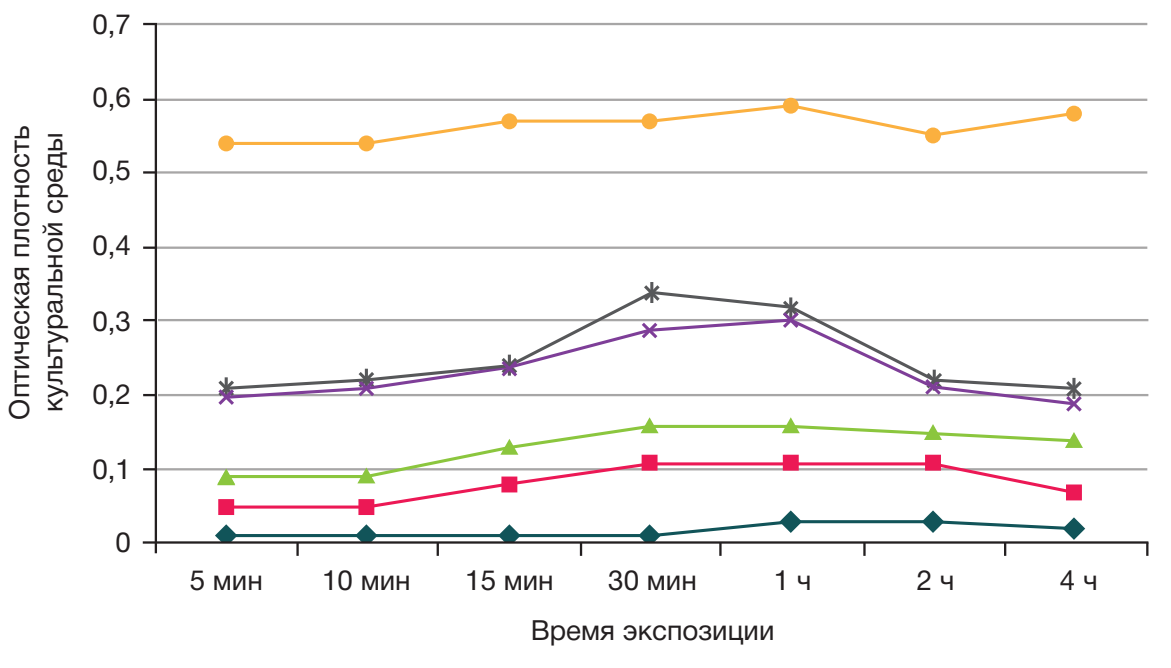

\footnotetext{
$\longrightarrow$ 1-е сутки $\rightarrow$ 2-е сутки $\longrightarrow$ 3-е сутки $\rightarrow$ 4-е сутки $\rightarrow$ 5-е сутки $\longrightarrow$ Контроль 5-е сутки
}

Рис. 3. Оптическая плотность культуральной среды с S. aureus ATCC 6538-P после экспозиций с азитромицином 


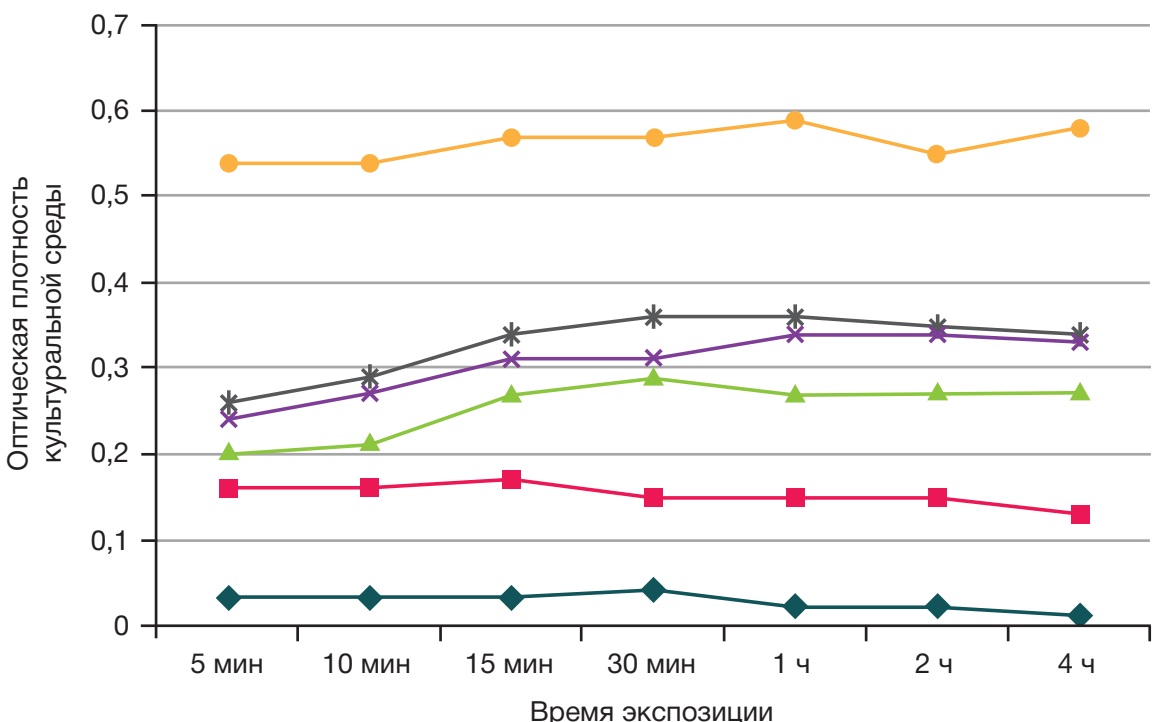

1-е сутки

2-е сутки

× 4-е сутки $\rightarrow$ - 5-е сутки

Контроль 5-е сутки

Рис. 4. Оптическая плотность культуральной среды с S. aureus ATCC 6538-P после экспозиций с соединением HD

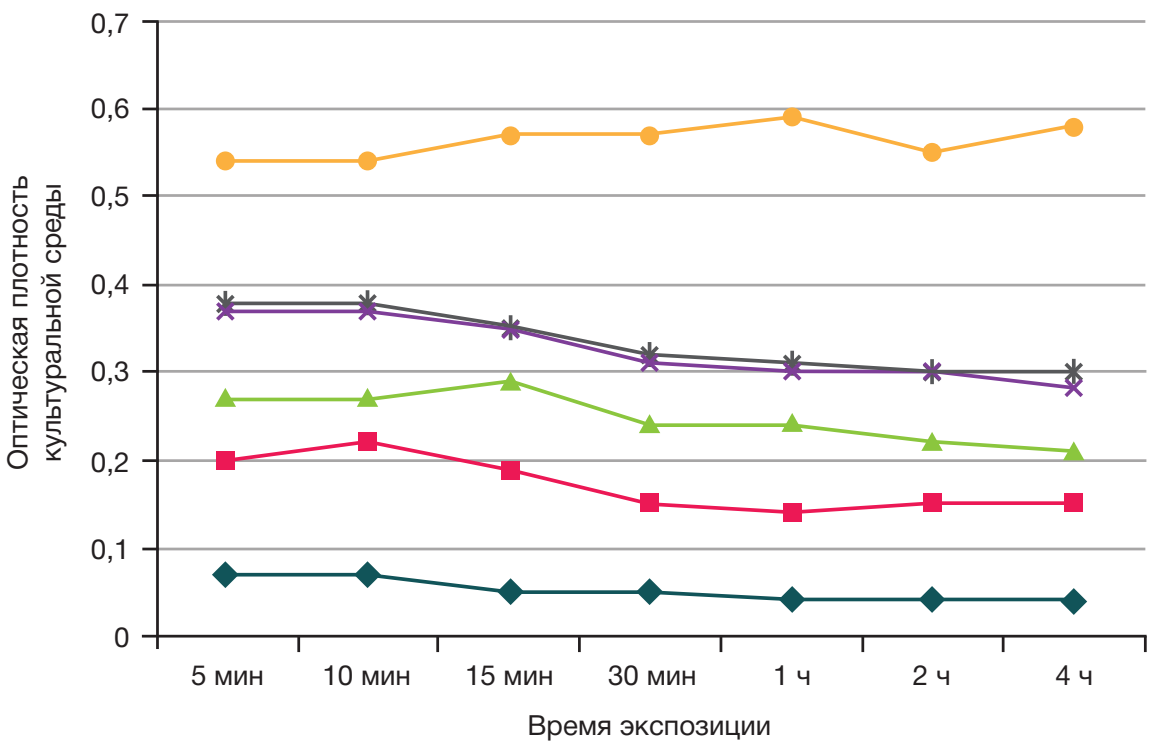

1-е сутки

2-е сутки

- 3-е сутки

* 4-е сутки $\rightarrow$ - 5-е сутки

Контроль 5-е сутки

Рис. 5. Оптическая плотность культуральной среды с S. aureus ATCC 6538-P после экспозиций с соединением S3

плотность культуральной жидкости содержащей МПК изучаемого соединения была ниже, чем в контроле. МПК исследуемого соединения HD задерживает рост и размножение микроорганизмов и оказывает в исследуемой концентрации бактериостатическое действие.

После экспозиций тест-штамма с соединением S3 видимого в проходящем свете роста в первые сутки не обнаружили. Через 2 суток культивирования наблюдали видимый рост в пробирках после экспозиции исследуемых микроорганизмов с амидом S3 в течение 5 мин, 10 мин и 15 мин, в остальных пробирках рост не вооруженным глазом в проходящем свете не выявили. На 3 сутки наблюдения обнаружили видимое помутнение среды во всех пробирках с посевами микроорганизмов. Изучаемый амид S3 статистически значимо задерживал увеличение значения $D$ культуральной среды с тест-штаммом S. aureus в первые и вторые сутки культивирования $(p<0,05)$ (табл.; рис. 5). В течение последующих суток культивирования отмечали тенденцию к задержке степени увеличения $D$ культуральной среды по сравнению с контролем.
Запоздалый (после 2 суток) рост микроорганизмов свидетельствует об отсутствии бактерицидного действия. МПК исследуемого соединения S3 задерживает рост и размножение микроорганизмов и оказывает в исследуемой концентрации бактериостатическое действие.

После экспозиций микроорганизмов с соединением 7D видимого в проходящем свете роста в первые сутки не наблюдали. Через 2 суток культивирования так же не выявили видимого не вооруженным глазом роста микроорганизмов. После 3 суток наблюдения обнаружили видимое помутнение среды с экспозицией вещества 7D в течение 30 мин. После 4 суток культивирования во всех пробирках наблюдали видимое в проходящем свете помутнение культуральной среды. Статистически значимое снижение плотности культуральной среды по сравнению с контролем наблюдали в течение 3 суток культивирования исследуемого тест-штамма S. aureus ATCC 6538-P после экспозиций с циклическим амидом 7D (табл.; рис. 6). На протяжении всего эксперимента наблюдали тенденцию к задержке роста микробной 


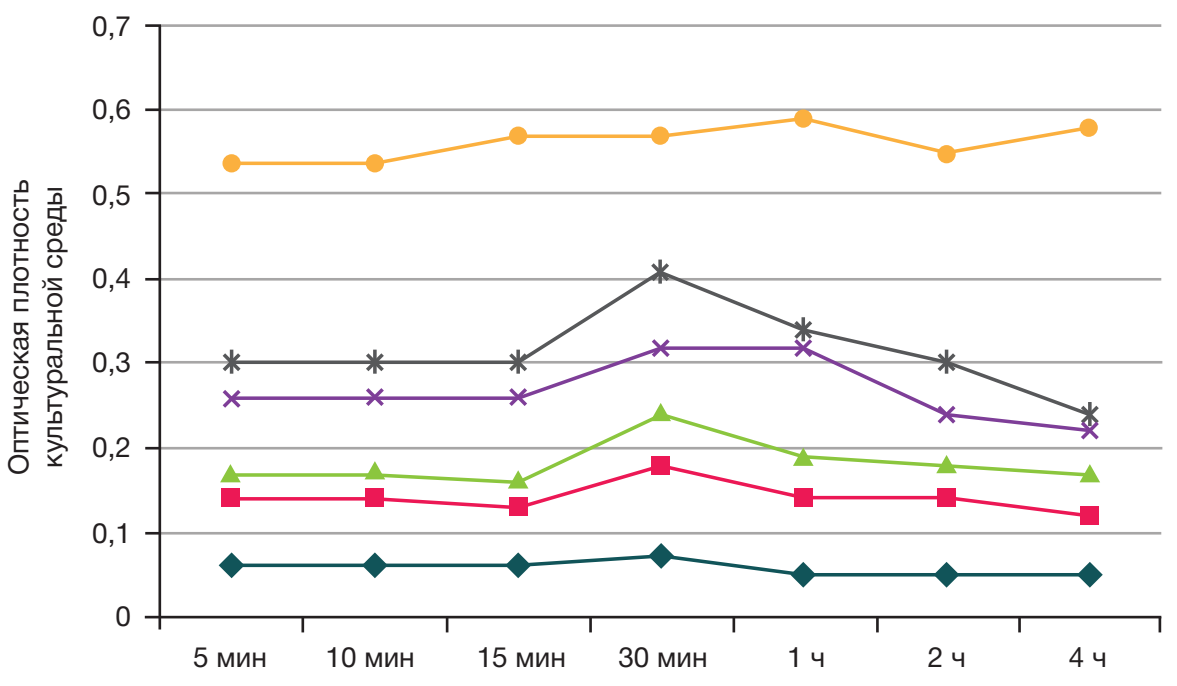

Время экспозиции

- 2-е сутки $\simeq$ 3-е сутки $\rightarrow$ 4-е сутки $\rightarrow$ * 5-е сутки Контроль 5-е сутки

Рис. 6. Оптическая плотность культуральной среды с S. aureus ATCC 6538-P после экспозиций с соединением 7D

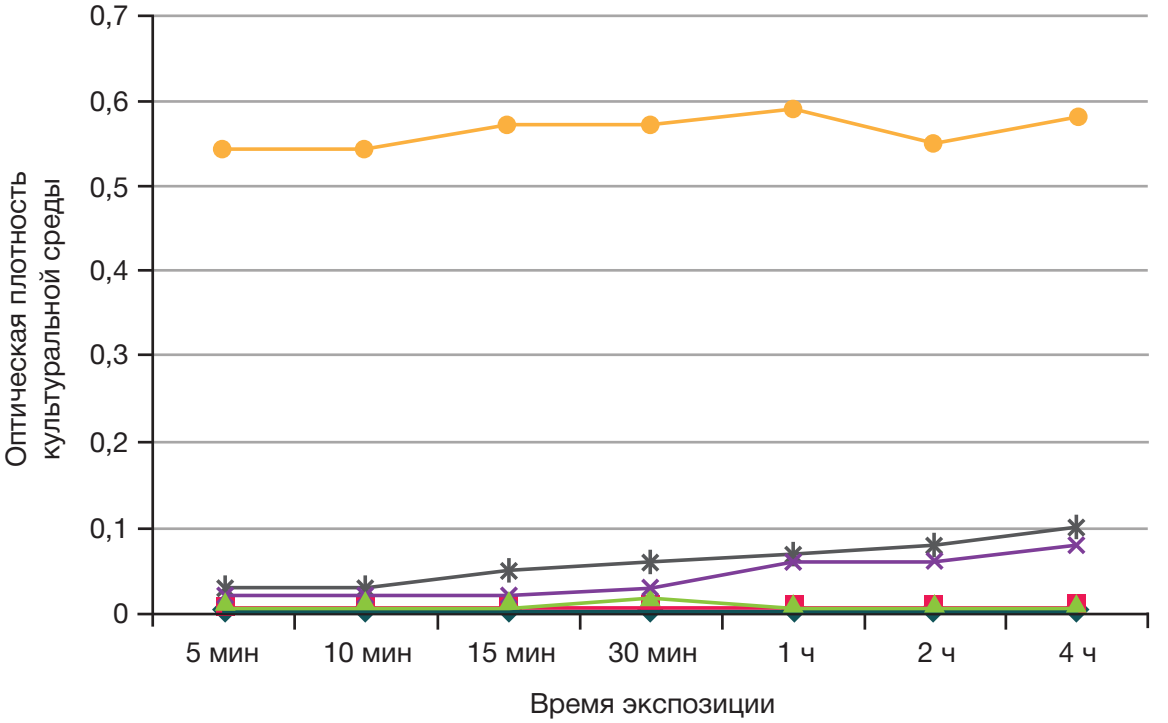

Рис. 7. Оптическая плотность культуральной среды с S. aureus ATCC 6538-P после экспозиций с соединением 5D

популяции в присутствии соединения 7D. Таким образом, МПK вещества 7D задерживает рост и размножение микроорганизмов и оказывает в исследуемой концентрации бактериостатическое действие.

Видимый в проходящем свете рост S. aureus ATCC 6538-P после экспозиций с циклическим амидом 5D в течение всего эксперимента не был обнаружен. Показатели оптической плотности культуральной средь в присутствии циклического амида 5D свидетельствовали о задержке роста и размножения исследуемого тестштамма S. aureus в течение 5 суток культивирования (табл.; рис. 7). Величина D культуральной среды статистически значимо отличалась от таковой в контроле $(p<0,05)$ в ходе эксперимента, но все же имела тенденцию к увеличению. Вероятно концентрация соединения 5D, полученная в среде, была близка к бактерицидной. Изучаемый циклический амид 5D задерживает рост и размножение микроорганизмов и оказывает в исследуемой концентрации бактериостатическое действие.
Таким образом, исследованные соединения, а именно циклический амид 5D (из группы соединений, полученных на основе 4-амино-фенилиндола), амид S3 и циклический амид 7D (из группы соединений, полученных на основе замещенных 6-аминоиндолов), а также циклический амид HD (из группы соединений, полученных на основе замещенных 7-аминоиндолов) в течение суток и более вызывали задержку роста и размножения тест-штамма $S$. aureus АТСС 6538-P. После культивирования в течение 2 суток все исследуемые соединения, кроме амида S3, продолжали подавлять рост исследуемого штамма микроорганизма. Видимый рост и соответствующее увеличение плотности культуральной среды через 2 суток наблюдали в пробирках c соединением S3 после экспозиций в течение 5 мин, 10 мин и 15 мин. После 3 суток видимый рост наблюдали во всех пробирках в присутствии циклического амида HD и амида S3. После 4 суток культивирования наблюдали видимый рост микроорганизмов в присутствии соединения 7D. Экспериментальное исследование в присутствии 
циклического амида 5D сопровождалось отсутствием видимого роста S. aureus ATCC 6538-P в течение 5 суток культивирования, хотя был обнаружен прирост микробной популяции по показателям оптической плотности среды.

Изученный тип противомикробного действия новых соединений, синтезированных на основе замещенных 4-, 6-, 7-аминоиндолов, обладающих наиболее выраженным противомикробным действием, сходен с действием препарата сравнения (азитромицина), классическим противомикробным препаратом с бактериостатическим действием.

\section{ОБСУЖДЕНИЕ РЕЗУЛЬТАТОВ}

В течение последних десятилетий неизменно актуальными остаются работы в области химии индола и его производных. Это обусловлено тем, что индольная структура лежит в основе многих природных и синтетических физиологически активных вещест, например молекулы незаменимой аминокислоты триптофана, биогенного амина серотонина. Особый интерес представляют аминоиндолы с аминогруппой в бензольной части молекулы. Эти соединения, как любые ароматические амины, имеют различного рода производные с участием аминогруппы [12-13]. Нами проводились исследования по изучению взаимодействия $\beta$-диоксосоединений с замещенными аминоиндолами с различным положением аминогруппы в бензольном кольце и были разработаны методы получения и синтезированы 16 исходных аминоиндолов и 32 их производных - индолиламидов, енаминов и пирролохинолонов. Определены МПК и спектры антимикробного действия полученных соединений.

В современной фармакологической науке исследование новых противомикробных соединений включает изучение МПК вещества, спектра противомикробного действия, типа противомикробного действия, механизма биологического действия и т. п. Методы определения типа противомикробного действия основаны на исследовании и сравнении МПК и минимальных бактерицидных концентраций (МБК) и дают возможность лишь условно классифицировать новое соединение по типу действия на бактериальную клетку
[16]. Методика определения типа противомикробного действия при воздействии исследуемых соединений в коротких экспозициях [15] позволила нам не только выявить тип противомикробного действия исследуемых соединений, но и доказать, что новые соединения при используемых временных экспозициях не изменяют свои противомикробные свойства, ни под действием окружающей среды, ни под действием микроорганизмов. В присутствии всех исследуемых соединений, не зависимо от наличия или отсутствия видимого роста микробной популяции, можно было наблюдать устойчивую тенденцию к задержке роста и размножения тест-штамма S. aureus ATCC 6538-P в течение всего эксперимента. Исходя из доказанного бактериостатического типа действия в МПК исследуемых соединений, можно предположить, что воздействие на клеточную стенку и цитоплазматическую мембрану микроорганизмов, приводящее к гибели микробной клетки, не является механизмом противомикробного действия группы изучаемых производных 4-, 6-, 7-аминоиндолов. Вероятно, активность исследуемых соединений обусловлена воздействием либо на ДНК микробной клетки (ДНКповреждающее действие или дополнительный механизм, не сопровождающийся образованием разрывов ДНК), либо на процессы, связанные с белковым синтезом. Изучение механизма противомикробного действия производных 4-, 6-, 7-аминоиндолов будет следующим этапом нашего исследования.

\section{ВЫВОДЫ}

В работе доказаны способность производных замещенных бензаминоиндолов в минимальных подавляющих концентрациях оказывать бактериостатическое действие и устойчивая тенденция к задержке роста и размножения тестштаммов микроорганизмов в присутствии производных 4-, 6-, 7-аминоиндолов. Полученные результаты являются основанием для дальнейшего исследования синтетических производных 4-, 6-, 7-аминоиндолов с целью клинического применения изученных соединений в качестве противомикробных препаратов.

\section{Литература}

1. Parhizgari N, Gouya MM, Mostafavi E. Emerging and re-emerging infectious diseases in Iran. Iranian Journal of Microbiology. 2017; 9 (3): 122-42.

2. Yokoyama M, Stevens E, Laabei M, Bacon L, Heesom K, Bayliss S et al. Epistasis analysis uncovers hidden antibiotic resistanceassociated fitness costs hampering the evolution of MRSA. Genome Biology. 2018; 19 (1): 94.

3. Kumarasamy KK, Toleman MA, Walsh TR, Bagaria J, Butt F, Balakrishnan $\mathrm{R}$ et al. Emergence of a new antibiotic resistance mechanism in India, Pakistan, and the UK: a molecular, biological, and epidemiological study. The Lancet Infectious Diseases. 2010; 10 (9): 597-602.

4. McKeegan KS, Borges-Walmsley MI, Walmsley AR. Microbial and viral drug resistance mechanisms. Trends in Microbiology. 2002; (10): 8-14.

5. Savjani JK, Gajjar AK, Savjani KT. Mechanisms of resistance: useful tool to design antibacterial agents for drug - resistant bacteria. Mini-Reviews in Medicinal Chemistry. 2009; 9 (2): 194-205.

6. Yadav N, Dubey A, Shukla S, Saini CP, Gupta G, Priyadarshini R et al. Graphene Oxide-Coated Surface: Inhibition of Bacterial

Biofilm Formation due to Specific Surface-Interface Interactions. ACS Omega. 2017; 2 (7): 3070-82

7. Obayiuwana A, Ogunjobi M, Yang M, Ibekwe M. Characterization of Bacterial Communities and Their Antibiotic Resistance Profiles in Wastewaters Obtained from Pharmaceutical Facilities in Lagos and Ogun States. Nigeria International Journal of Environmental Research and Public Health. 2018; 15 (7): 1365.

8. Козлов Р. С. Антибиотикорезистентность грамположительных возбудителей осложненных интраабдоминальных инсекций в России. Клиническая микробиология и антимикробная химиотерапия. 2015; 17 (3): 227-34.

9. Романов А. В. Антибиотикорезистентность нозокомиальных штаммов Staphylococcus aureus в стационарах России: результаты многоцентрового эпидемиологического исследования «Марафон» 2013-2014. Клиническая микробиология и антимикробная химиотерапия. 2017; 19 (1): 57-62.

10. Сухорукова М. В. Антибиотикорезистентность нозокомиальных штаммов Enterobacteriaceae в стационарах России: результаты многоцентрового эпидемиологического исследования «Марафон» 
2013-2014. Клиническая микробиология и антимикробная химиотерапия. 2017; 19 (1): 49-56.

11. Распоряжение Правительства РФ от 25 сентября 2017 г. № 2045-р «О стратегии предупреждения распространения антимикробной резистентности В РФ на период до 2030 г.». Доступно по ссылке: https://www.garant.ru/products/ipo/prime/ doc/71677266/.

12. Алямкина Е. А., Степаненко И. С., Ямашкин С. А., Юровская М. А. Соединения с потенциальной антимикробной активностью на основе 4-амино-2-фенилиндола. Вестник Московского университета. 2016; 57 (6): 410-17.

13. Alyamkina EA, Yamashkin SA, Stepanenko IS, Yurovskaya MA. 4-amino-2-phenylindole-based compounds with potential antibacterial activity. Moscow University Chemistry Bulletin. 2017; $72(1): 24-8$.

14. Stepanenko IS. A new group of compounds derived from 4-, 5-, 6- and 7-aminoindoles with antimicrobial activity. Research Results in Pharmacology. 2018; 4 (3): 17-26.

\section{References}

1. Parhizgari N, Gouya MM, Mostafavi E. Emerging and re-emerging infectious diseases in Iran. Iranian Journal of Microbiology. 2017; 9 (3): 122-42.

2. Yokoyama M, Stevens E, Laabei M, Bacon L, Heesom K, Bayliss S et al. Epistasis analysis uncovers hidden antibiotic resistanceassociated fitness costs hampering the evolution of MRSA. Genome Biology. 2018; 19 (1): 94.

3. Kumarasamy KK, Toleman MA, Walsh TR, Bagaria J, Butt F, Balakrishnan $\mathrm{R}$ et al. Emergence of a new antibiotic resistance mechanism in India, Pakistan, and the UK: a molecular, biological, and epidemiological study. The Lancet Infectious Diseases. 2010; 10 (9): 597-602.

4. McKeegan KS, Borges-Walmsley MI, Walmsley AR. Microbial and viral drug resistance mechanisms. Trends in Microbiology. 2002; (10): 8-14.

5. Savjani JK, Gajjar AK, Savjani KT. Mechanisms of resistance: useful tool to design antibacterial agents for drug - resistant bacteria. Mini-Reviews in Medicinal Chemistry. 2009; 9 (2): 194-205.

6. Yadav N, Dubey A, Shukla S, Saini CP, Gupta G, Priyadarshini R et al. Graphene Oxide-Coated Surface: Inhibition of Bacterial Biofilm Formation due to Specific Surface-Interface Interactions. ACS Omega. 2017; 2 (7): 3070-82.

7. Obayiuwana A, Ogunjobi M, Yang M, Ibekwe M. Characterization of Bacterial Communities and Their Antibiotic Resistance Profiles in Wastewaters Obtained from Pharmaceutical Facilities in Lagos and Ogun States. Nigeria International Journal of Environmental Research and Public Health. 2018; 15 (7): 1365.

8. Kozlov RS. Antibiotic resistance of gram-positive pathogens of complicated intra-abdominal infections in Russia. Clinical microbiology and antimicrobial chemotherapy. 2015; 17 (3): 227-34.

9. Romanov AV. Antibiotic resistance of nosocomial strains of Staphylococcus aureus in hospitals in Russia: results of the Marathon 2013-2014 multicenter epidemiological study. Clinical microbiology and antimicrobial chemotherapy. 2017; 19 (1): 57-62.

10. Sukhorukova MV. Antibiotic resistance of nosocomial
15. Першин Г. Н. редактор. Практическое руководство. Методы экспериментальной химиотерапии. М.: Медицина, 1971; 541 с.

16. Миронов А. Н., Бунятян Н. Д., Васильев А. Н., Верстакова О. Л., Журавлева М. В., Лепахин В. К. и др. Руководство по проведению доклинических исследований лекарственных средств. М.: Грисф и К, 2012; 944 с.

17. Определение чувствительности микроорганизмов $k$ антибактериальным препаратам. Методические указания МУК 4.2.1890-04. Клиническая микробиология и антимикробная химиотерапия. 2004; 6 (4): 303-402.

18. Козлов Р. С., Сухорукова М. В., Эйдельштейн М. В., Иванчик Н. В., Склеенова Е. Ю., Тимохова А. В. и др. Определение чувствительности микроорганизмов $\mathrm{K}$ антимикробным препаратам: клинические рекомендации. Смоленск: Межрегиональная ассоциация по клинической микробиологии и антимикробной химиотерапии. 2018; 206 с.

Enterobacteriaceae strains in hospitals in Russia: the results of the Marathon 2013-2014 multicenter epidemiological study. Clinical microbiology and anti-microbial chemotherapy. 2017; 19 (1): 49-56.

11. Rasporyazheniye Pravitel'stva RF ot 25 sentyabrya $2017 \mathrm{~g}$. № 2045-r «O strategii preduprezhdeniya rasprostraneniya antimikrobnoy rezistentnosti v RF na period do 2030 g.». Available from: https://www.garant.ru/products/ipo/prime/doc/71677266/. Russian.

12. Alyamkina EA, Stepanenko IS, Yamashkin SA, Yurovskaya MA. Soedineniya s potencial'noj antimikrobnoj aktivnost'yu na osnove 4-amino-2-fenilindola. Vestnik Moskovskogo universiteta. 2016; 57 (6): 410-7. Russian.

13. Alyamkina EA, Yamashkin SA, Stepanenko IS, Yurovskaya MA. 4-amino-2-phenylindole-based compounds with potential antibacterial activity. Moscow University Chemistry Bulletin. 2017; 72 (1): 24-8.

14. Stepanenko IS. A new group of compounds derived from 4-, 5-, 6- and 7-aminoindoles with antimicrobial activity. Research Results in Pharmacology. 2018; 4 (3): 17-26.

15. Pershin GN, redaktor. Prakticheskoe rukovodstvo. Metody ehksperimental'noj himioterapii. M.: Medicina, 1971; 541 s. Russian.

16. Mironov AN, Bunyatyan ND, Vasilyev AN, Verstakova OL, Zhuravleva W, Lepakhin VK, i dr. Rukovodstvo po provedeniju doklinicheskih issledovanij lekarstvennyh sredstv. M.: Grif i K, 2012; 944 s. Russian.

17. Opredelenie chuvstvitel'nosti mikroorganizmov $k$ antibakterial'nym preparatam. Metodicheskie ukazanija MUK 4.2.1890-04. Klinicheskaja mikrobiologija i antimikrobnaja himioterapija. 2004; 6 (4): 303-402. Russian.

18. Kozlov RS, Sukhorukova MV, Eidelstein MV, Ivanchik NV, Skleenova EYu, Timokhova AV, et al. Determination of the sensitivity of microorganisms to antimicrobial drugs: clinical recommendations. Smolensk: Interregional Association of Clinical Microbiology and Antimicrobial Chemotherapy. 2018; 206 p. 